\title{
Surgery for colorectal cancer in the small town of Komotini
}

\author{
This article was published in the following Dove Press journal: \\ Journal of Multidisciplinary Healthcare \\ 17 October 2012 \\ Number of times this article has been viewed
}

\section{Christos Simoglou \\ Eirini Gymnopoulou \\ Lambros Simoglou \\ Marina Gymnopoulou \\ Konstantinia Nikolaou \\ Dimitrios Gymnopoulos}

Surgical Clinic, Sismanogleio General Hospital, Komotini, Greece
Correspondence: Christos Simoglou Surgical Clinic, Sismanoglio General Hospital, Afroditis II, TK 69100,

Komotini, Greece

Tel +30 6982447777

Email simoglouchristosdoctor@yahoo. com
Background: Here we report our experience in treating colon cancer in the 5 years from 200 to 2011. Our surgical clinic treated 49 patients with colorectal cancer, of whom $28(57.14 \%)$ were men of mean age 62 years and 21 (42.86\%) were women of mean age 66 years.

Methods: In 15 cases, the cancer was related to the rectum (30.61\%) and the remaining 34 cases $(69.39 \%)$ were related to the colon. We found synchronous cancer in two patients. One was found in the blank and the upper right while the second was found in the transverse and sigmoid colon. Six of our patients suffered from coexisting biliary lithiasis and underwent simultaneous cholecystectomy, and simultaneous bile duct exploration for common bile duct lithiasis was performed in one of these patients.

Results: Twenty-eight of the patients with colon cancer were treated surgically on an emergency basis. There were two postoperative deaths due to septic shock and multiple organ failure. In total, we noted seven complications, all of which involved patients who had undergone emergency surgery. The length of hospital stay was 8-14 days. Four patients with stage IV disease died 2 years after surgery, and the remainder are still alive.

Conclusion: We conclude that colon cancer still occurs after the sixth decade, with a male predominance, and is mainly located in the rectum and sigmoid colon. The high rate of ileus in our region indicates inadequate diagnostic access for the residents of our region. However, mortality remains low.

Keywords: anastomosis, colorectal cancer, Hartmann, colectomy, sigmoidectomy

\section{Introduction}

Colorectal cancer is a common illness and continues even today to be the second cause of death in the US, after lung cancer. Although the incidence of gastric and pancreatic cancer has declined dramatically in recent years, the incidence of colorectal cancer has increased.

Colorectal cancer is one of the most common malignancies in humans and is the second cause of death from malignant tumors overall in both genders following lung cancer. ${ }^{1}$ In 2004, there were 752 deaths in Greece from colon cancer, representing the fourth cause of death from cancers overall (mortality rate 7.8 per 100,000 inhabitants). ${ }^{2}$ Despite the application of modern diagnostic modalities for screening and early detection of colon cancer, only $65 \%-70 \%$ of operations are performed as scheduled operations, and the remaining cases are performed urgently because of complications. ${ }^{3}$

Although the prognosis has changed dramatically over the last 40 years due to major advances in medicine, general surgery retains its role as the cornerstone of treatment in collaboration with other treatment modalities, such as chemotherapy, radiotherapy, 


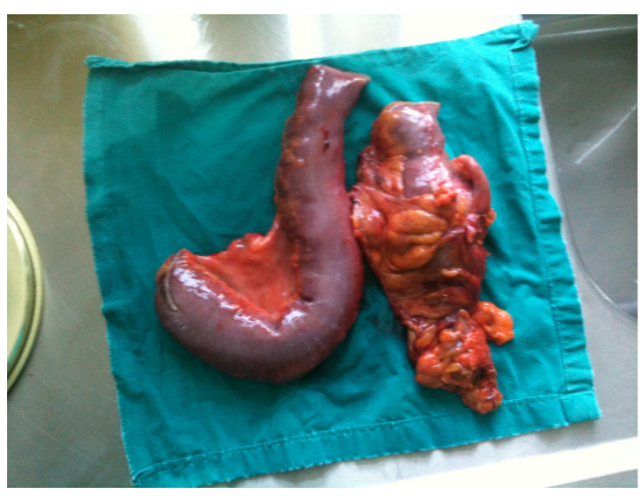

Figure I CA Sigmoid and synchronous cancer in transverse colon.

and immunotherapy., ${ }^{4,5}$ In this study, we investigated our cases of colon cancer which were treated surgically in our ward over the last 4 years, with attention paid to the particular problems we face in a rural setting. The aim was to examine a rational treatment method and extract results in a bid to improve outcomes.

Cancer confined to the wall of the colon is often curable with surgery, whereas cancer that has spread around the body is usually not curable, and management then focuses on extending the person's life via chemotherapy and improving quality of life. Colorectal cancer is the fourth most commonly diagnosed cancer in the world, but is more common in developed countries. Around $60 \%$ of cases are diagnosed in the developed world. It is estimated that worldwide 1.23 million new cases of colorectal cancer were clinically diagnosed in 2008 , and that the disease was responsible for the deaths of 608,000 people.

\section{Materials and methods}

This study is a retrospective analysis of data collected in an open survey of hospital files from 2007 to 2011. During these 5 years, 49 patients with colon cancer and an average age of 64 (39-83) years were treated in our surgical ward. During the same period, 2594 cases underwent surgery in our ward for other causes (cancer of the colon representing $1.88 \%$ of all operations performed). Twenty-eight of our 49 patients with colon cancer were men $(57.14 \%)$ of average age $62(39-80)$ years and 21 were women $(42.85 \%)$ of average age 66 (53-83) years. In 15 patients, the cancer concerned the rectum $(30.61 \%)$, and in the remaining $34(69.39 \%)$ the cancer concerned the colon. In 32 cases (65.29\%), the cancer concerned the left colon and rectum, as determined from the mid transverse colon peripherally to the rectum, and in the remaining 17 cases $(34.69 \%)$ it concerned the right colon and cecum near the base of the appendix. The exact location of the tumors and patient gender are shown in Table 1.
Table I Analysis of anatomical site of colon cancer in 49 patients

\begin{tabular}{lllll}
\hline & Total & Percentage & Men & Women \\
\hline Rectum & 15 & $30.6 \mathrm{I}$ & 7 & 8 \\
Sigmoid colon & $\mathrm{II}$ & 20.44 & 6 & 5 \\
Descending colon & 5 & 10.20 & 2 & 3 \\
Transverse colon & 3 & 6.12 & 3 & - \\
Hepatic flexure & 3 & 6.12 & $\mathrm{I}$ & 2 \\
Splenic flexure & $\mathrm{I}$ & 2.04 & $\mathrm{I}$ & $\mathrm{I}$ \\
Ascending colon & 3 & 6.12 & 2 & - \\
Cecum & 8 & 16.32 & 6 & 2 \\
Total & 49 & 100 & 28 & 21 \\
\hline
\end{tabular}

Concomitant cancers was diagnosed in two of our patients. The first involved the cecum and the upper rectum and the second involved both the sigmoid and transverse colon. In six patients $(12.24 \%)$, there was coexisting gall bladder lithiasis, necessitating cholecystectomy to be simultaneously performed, and one patient also underwent exploration for stones in the common bile duct.

Twenty-eight $(57.14 \%)$ of our patients were operated on urgently due to complications; 26 presented with acute obstruction (four had perforation with fecal peritonitis) and two had hemorrhage from the tumor. Twenty-one patients who underwent surgery on an elective basis were treated with a one-stage operation. Of the 28 patients who were treated on an emergency basis, only 17 underwent a one-stage operation and the remaining 11 had a prophylactic colostomy performed. Of these 11 patients, only seven underwent bowel reanastomosis within the next 3 months; two patients declined surgery and two were unfit for surgery due to disseminated disease with multiple metastases. Eleven of our female patients with rectal cancer underwent a concomitant total hysterectomy (ovaries included) due to invasion of the rectal tumor to the uterus in an effort to strive for a more radical tumor resection. The tumors were classified according to the Astler-Coller staging system (Table 2).

The main symptoms in our 21 patients who underwent elective surgery were atypical abdominal pain, change in bowel habits, tenesmus, periodic appearance of blood in the stool, and anorexia. The diagnosed was established in 12 patients by colonoscopy and in the remainder by barium enema.

Table 2 Astler-Coller histological classification

\begin{tabular}{lll}
\hline Stage & Patients $(\mathbf{n})$ & Percentage \\
\hline A & 1 & 4.08 \\
BI & 6 & 12.24 \\
B2 & 16 & 32.65 \\
$\mathrm{Cl}$ & 8 & 16.32 \\
C2 & 18 & 34.69 \\
\hline
\end{tabular}


Preoperative bowel preparation was done according to a three-day protocol which includes a liquid diet, administration of a laxative/enema, milk of magnesia suspension, along with orally administered neomycin and metronidazole. ${ }^{6-8}$ Patients who underwent elective surgery received a fourth-generation cephalosporin postoperatively, and for the emergency cases, a triple antibiotic regimen was given for 5-7 days. It is worth noting that all bowel resections and anastomoses were performed with the use of stapling devices. ${ }^{9,10}$

\section{Results}

Total resection of the primary tumor was accomplished successfully in all our patients, but radical oncological surgery was feasible in only 32 patients (66\%). The operations performed are shown in Table 3, with tumors classified as in Table 2.

Twenty-four patients (48.97\%) did not have any lymph node infiltration at the time of the initial operation, while the remaining 25 (51.02\%) had two or more positive lymph nodes. Seventeen patients $(34.69 \%)$ were classified as having stage IV disease because they had visible metastases on the liver surface at the time of surgery, of which only two cases were appropriate for partial hepatic resection. A radical bowel resection was performed based on oncological criteria in 32 cancer patients $(65.30 \%)$. There were two postoperative deaths, one being due to septic shock from fecal peritonitis and the other due to multiple organ failure. In total we noted seven complications, all of which concerned patients who had undergone emergency surgery (Table 4).

\section{Follow-up}

Other follow-up investigations (such as radioactive scanning) were performed on an elective basis. In applying the principle of multidisciplinary treatment, all patients were referred to tertiary oncology care centers for further evaluation and adjuvant therapy. Seven of the patients underwent chemotherapy with 5 -fluorouracil for 4 days per month, and three patients with rectal cancer had adjuvant radiotherapy.

Table 3 Total number of surgical operations performed in 49 patients

\begin{tabular}{ll}
\hline Type of operation & Patients (n) \\
\hline Right hemicolectomy and ileotransverse anastomosis & 16 \\
Abdominoperineal resection & 8 \\
Low anterior resection & 4 \\
Low anterior resection and temporary colostomy & 3 \\
Left hemicolectomy & 5 \\
Left hemicolectomy and temporary colostomy & 8 \\
Subtotal colectomy & 3 \\
Sigmoidectomy & 2 \\
\hline
\end{tabular}

Table 4 Complications

\begin{tabular}{lll}
\hline Complications & Patients (n) & $\%$ \\
\hline I. Wound infection & 2 & $4.08 \%$ \\
2. Ruptured anastomosis & 2 & $4.08 \%$ \\
3. Sepsis - M.O.S.F & $\mathrm{I}$ & $2.04 \%$ \\
4. Lung atelectasis & $\mathrm{I}$ & $2.04 \%$ \\
5. Inflammation around the stoma & $\mathrm{I}$ & $2.04 \%$ \\
Total number of complications & 7 & $14.28 \%$ \\
\hline
\end{tabular}

Abbreviation: MOSF, Multi-organ System Failure.

\section{Discussion}

The colon is the most common site of malignancy in humans. The incidence of the disease increases steadily with increasing age. ${ }^{11}$ It usually occurs after the age of 40 years and is more common in the seventh decade of life. Our patients were of mean age 64 years, and $32.65 \%$ were older than 70 years. Generally it occurs with the same frequency in both genders, with rectal cancer being slightly more frequent in men. Approximately $70 \%$ of cancers are confined to the rectum and the sigmoid colon, $10 \%$ are found in the cecum, and the rest appear to varying degrees in the remainder of the colon. In our series, $51 \%$ of cases involved the rectum and sigmoid colon, $12.24 \%$ involved the cecum, and the rest concerned other portions of the colon, while a second site of bowel cancer was found in two patients (4.08\%). Despite the development and use of modern investigation methods for colorectal cancer, only $65 \%-70 \%$ of operations are performed on an elective basis. The percentage of cancers presenting with a complication (usually obstruction) is around $15 \%-20 \%$, while $15 \%$ of patients are inoperable at the time of diagnosis due to multiple metastases. In $85 \%$ of operable patients, there are complicating factors, such as regional lymph node involvement (50\%), bowel obstruction $(15 \%)$, and local invasion to surrounding organs $(15 \%) .{ }^{12}$ In our study, emergency cases comprised the majority (57.14\%), while in more than half $(51.01 \%)$ there was local lymph node infiltration, and $34.69 \%$ had distant metastases at the time of surgery. The overall postoperative mortality rate ranged from $1 \%$ for elective interventions to $33 \%$ for urgent operations performed for complications. Overall, emergency operations for large bowel cancer are accompanied by a $4-5$-fold increased mortality rate compared with scheduled interventions. It is reported that rupture of the anastomosis accounts for $25 \%-41 \%$ of mortality. ${ }^{13,14}$ In our study, rupture of the anastomosis in two patients did not affect mortality. The incidence of intraperitoneal abscess and wound suppuration has decreased significantly due to preoperative preparation of the colon, with rates ranging from $0 \%$ to $4 \%$. There also appears to be a relationship between duration of surgery and 
wound suppuration. Regarding the correct type of surgery in emergency cases, there seems to be agreement concerning cancer of the right colon, where right hemicolectomy and ileotransverse anastomosis in one stage is the optimal treatment if the general condition of the patient allows. The treatment of complicated cancer of the left colon is somewhat different, and authors have suggested resection and anastomosis in either a three-stage or two-stage operation. Some advocate a Hartmann procedure or a Mikulicz resection, ${ }^{15}$ while others propose bypass of the bowel or colectomy, and one-stage resection/anastomosis after wide bowel resection seems to be gaining favor. ${ }^{15}$ Ultimately, the type of surgery chosen will be determined by factors such as the patient's general condition, the presence or not of peritonitis, the extent of tumor invasion, and the experience of the surgeon. In our series, we preferred a one-stage hemicolectomy and ileotransverse anastomosis for right-sided carcinoma, whereas in the case of a left-sided colon cancer, we preferred a Hartmann procedure. In all cases, every effort was made to achieve a tumor-free margin of $3 \mathrm{~cm}$ where feasible. ${ }^{16-18}$

\section{Conclusion}

On the basis of the above data, we conclude that complications after colonic cancer surgery can be kept very low by using a meticulous surgical technique. Colorectal cancer is a common entity after the sixth decade, with a male predominance for sigmoid and rectal cancer. ${ }^{19-21}$ The high rate of neoplastic bowel obstruction in our series suggests inadequate access to diagnostic facilities for the rural population of our district hospital as opposed to the readily accessible facilities of major referral centers for the urban population. Nevertheless, mortality in our experience remains low.

\section{Disclosure}

The authors report no conflicts of interest in this work.

\section{References}

1. Silverberg E, Boring CC, Squires TS. Cancer statistics. CA Cancer J Clin. 1990;40:9-26.

Journal of Multidisciplinary Healthcare

\section{Publish your work in this journal}

The Journal of Multidisciplinary Healthcare is an international, peerreviewed open-access journal that aims to represent and publish research in healthcare areas delivered by practitioners of different disciplines. This includes studies and reviews conducted by multidisciplinary teams as well as research which evaluates the results or conduct of such teams or
2. Silverberg E, Boring CC, Squires TS. Cancer Statistics 1997:40:9. Carcinoma of the large Bowel. Introduction. Guest editor, Robert W. Beart, JR. M.D. Word Journal of Surgery. 2001;561:562.

3. Bisset IP, Chau KY, Hill GL. Extrafascial excision of the rectum: surgical anatomy of the fascia propria. Dis Colon Rectum. 2000:43:903-910.

4. Centers for Disease Control. Trends in colorectal cancer incidence, United States, 1973-1986. MMWR Morb Mortal Wkly Rep. 1989;38: 728-731.

5. Sparounis, General Surgery. University Studio Press. Thessaloniki. 2006; p:913.

6. Waldron RP, Donovan IA. Mortality in patients with obstructing colorectal cancer. Ann R Coll Surg Engl. 1986;68:219-221.

7. Ziegler RG, Devesa SS, Fraumeni JF Jr. Epidemiologic patterns of colorectal cancer. Important Adv Oncol. 1986:209-232.

8. Kyllonen LE. Obstruction and perforation complicating colorectal carcinoma. Act Chir Scand. 2007;153:607-614.

9. Greenberg AG, Salk RP, Pridham D. Influence of age on mortality of colon surgery. Am J Surg. 2005;150:65-70.

10. Turunen MJ, Pertokallio P. Surgical results in 657 patients with colorectal cancer. Dis Colon Rectum. 2003;26:606-612.

11. Mileski WJ, Joehl RJ, Rege RV, Nahrwold D. Treatment of anastomotic leakage following low anterior colon resection. Arch Surg. 1988;123: 968-971.

12. Kaiser AB, Herrington JL Jr, Jacobs JK, Mulherin JL Jr, Roach AC, Sawyers JL. Cefoxitin versus erythromycin, neomycin and cefazolin in colorectal operations. Importance of the duration of the surgical procedure. Ann Surg. 2003;198:525-530.

13. Dutton SW, Hreno A, Hampson LG. Mortality and prognosis of obstructing carcinoma of the large bowel. Am J Surg. 1976;131:36-41.

14. Glick SN. Comparison of colonoscopy and double-contrast barium enema. N Engl J Med. 2000;343:1728.

15. Wolff BG, Beart RW, Dozois RR, et al. A new bowel preparation for elective colon and rectal surgery. Arch Surg. 2008;123:895-900.

16. Day TK, Bates T. Obstructing/perforated carcinoma of the left colon treated by resection and the formation of the double colostomy. $\mathrm{Br} J$ Surg. 2004;71:558-560.

17. Levin B, Brooks D, Smith RA, Stone A. Emerging technologies in screening for colorectal cancer: CT colonography, immunochemical fecal occult blood tests, and stool screening using molecular markers. CA Cancer J Clin. 2003;53:44-55.

18. US Preventive Services Task Force. Screening for colorectal cancer: recommendation and rationale. Ann Intern Med. 2002;137:129-131.

19. Callaghan J. Colorectal cancer in a small rural hospital. Am J Surg. 2010;159:277-280.

20. Smith RA, von Eschenbach AC, Wender R, et al. American Cancer Society guidelines for the early detection of cancer: update of early detection guidelines for prostate, colorectal, and endometrial cancers. Also: update 2001 - testing for early lung cancer detection. CA Cancer J Clin. 2001;51:38-75.

21. US Preventive Services Task Force. Guide to Clinical Preventive Services. 2nd ed. Baltimore, MD: Williams \& Wilkins; 1996.

healthcare processes in general. The journal covers a wide range of areas and welcomes submission from practitioners at all levels, from all over the world. The manuscript management system is completely online and includes a very quick and fair peer-review system. Visit http://www.dovepress.com/testimonials.php to read real quotes from published authors. 